\title{
Integrin $\beta 3$ and CD44 levels determine the effects of the OPN-a splicing variant on lung cancer cell growth
}

\author{
Shih-Jung Sun ${ }^{1, *}$, Chun-Chi Wu ${ }^{1, *}$, Gwo-Tarng Sheu ${ }^{1}$, Hui-Yi Chang ${ }^{2}$, Mei-Yu Chen ${ }^{2}$, \\ Yu-Ying Lin', Cheng-Yen Chuang ${ }^{2,3}$, Shih-Lan $\mathrm{Hsu}^{4}$, Jinghua Tsai Chang ${ }^{1,2,5}$ \\ ${ }^{1}$ Institute of Medicine, Chung Shan Medical University, Taichung, Taiwan, ROC \\ ${ }^{2}$ Institute of Medical and Molecular Toxicology, Chung Shan Medical University, Taichung, Taiwan, ROC \\ ${ }^{3}$ Division of Thoracic Surgery, Taichung Veterans General Hospital, Taichung, Taiwan, ROC \\ ${ }^{4}$ Department of Education \& Research, Taichung Veterans General Hospital, Taichung, Taiwan, ROC \\ ${ }^{5}$ Department of Chest Medicine, Chung Shan Medical University Hospital, Taichung, Taiwan, ROC \\ *These authors have contributed equally to this study \\ Correspondence to: Jinghua Tsai Chang, email: jinghuat@csmu.edu.tw \\ Keywords: OPN-a, integrin $\beta 3, C D 44, N F-k B$ \\ Received: November 25, $2015 \quad$ Accepted: June 07, $2016 \quad$ Published: July 27, 2016
}

\section{ABSTRACT}

Osteopontin (OPN), a phosphorylated glycoprotein, is frequently overexpressed in cancer. Among the three OPN isoforms, OPN-a is the most highly expressed in lung cancer cell lines and lung tumors. Overexpression of OPN-a greatly reduced CL1-5 lung adenocarcinoma cell growth, but had no effect on growth in A549 lung adenocarcinoma cells. Examination of the expression of integrins and CD44, which are possible OPN-a receptors, revealed that differences in integrin $\beta 3$ levels might explain this discrepancy between CL1-5 and A549 cells. When integrin $\beta 3$ was ectopically expressed in A549 cells, OPN-a inhibited their growth, whereas OPN-a increased cell growth following integrin $\beta 3$ knockdown in CL1-5 cells. This OPN-a-induced increase in growth appeared to result from activation of the CD44/NFKB pathway. Our results demonstrated that OPN-a inhibits growth of cells with high integrin $\beta 3$ levels and increases growth via activation of the CD44/NFKB pathway in cells with low integrin $\beta 3$ levels. Thus, OPN-a, integrin $\beta 3$, and CD44 interact to affect lung cancer cell growth, and this study may aid in the development of cancer treatment strategies involving these molecules.

\section{INTRODUCTION}

Osteopontin (OPN) is a multifunctional phosphorylated glycoprotein and an inducible marker secreted by transformed, malignant epithelial cells [1]. It is expressed in a wide range of cells and regulates many biological functions, including immune responses, tissue remodeling, and vascularization, through its effects on two types of cell adhesion molecules: integrins [2, $3]$ and CD44 [4, 5]. OPN is also involved in tumorassociated proliferation [6, 7], survival [8], adhesion [9, $10]$, migration [11, 12], invasion, and angiogenesis [13]. Increased expression of OPN is associated with reduced progression and metastasis in lung $[14,15]$, breast [11, 16], colon [17], liver [18], stomach [12], and prostate [19] cancer.
Several isoforms of OPN transcripts have been identified, including OPN-a (full-length form), OPN-b (lacking exon 5), and OPN-c (lacking exon 4) (Figure 1A) [20]. Numerous studies addressing the roles of these isoforms in tumorigenesis yielded conflicting results. In breast cancer, OPN-c is more effective in enhancing anchorage-independent growth than OPN-a [21]. In hepatocellular carcinoma cell lines, OPN-a and -b, but not OPN-c, induce cell migration in SK-Hep1 cells with robust migratory capacity. Conversely, OPN-c, but not OPN-a, represses migration in Hep3B cells. OPN-c also promotes the formation of adhesive foci in Hep3B cells [22]. In PC-3 prostate cancer cells, OPN-b and OPN-c overexpression promote tumorigenesis [23]. In nonsmall cell lung cancer (NSCLC) cell lines, OPN-a and OPN-b enhance, while OPN-c suppresses, cell invasion. 
Moreover, while OPN-a enhances and OPN-c suppresses colony formation, OPN-b has inconsistent effects [24].

We have observed that $65 \%$ of NSCLC specimens express high levels of OPN protein [25]. The predominant form of OPN expressed in lung cancer cell lines and lung tumors is OPN-a. In the absence of integrin $\beta 3$ (ITG 33 ), OPN-a enhances cell growth through the CD44/ $\mathrm{NF} \kappa \mathrm{B}$ pathway. When OPN-a levels are low, ITG $\beta 3$ is essential for CL1-5 lung cancer cell growth. However, OPN-a inhibits lung cancer cell growth in the presence of high levels of ITG $\beta 3$. The aim of this study was to investigate the effects of ITG 33 and CD44, two important growth-enhancing molecules in lung cancer cells, on the regulatory role of OPN-a in lung cancer cell growth.

\section{RESULTS}

\section{OPN splicing affects lung cancer cell growth}

Overexpression of OPN has been implicated in tumor growth and invasion in various cancers, including lung cancers. However, a number of highly-invasive lung cancer cell lines, such as A549, H1299, and CL1-5, expressed low levels of OPN protein (Figure 1B). Among the three OPN isoforms, OPN-a was the most highly- expressed isoform in lung cancer cell lines and tumors (Figure 1C).

OPN-a, OPN-b, and OPN-c splicing variants were cloned and transiently transfected into CL1-5 and A549 cells. These ectopically expressed OPN proteins were also secreted into culture medium (Figure 2A). To determine the effects of the different OPN splicing variants on cell growth, we treated CL1-5 cells with conditioned medium (CM) from other CL1-5 cells transiently transfected with different OPN isoforms. Surprisingly, CL1-5 cells treated with $\mathrm{CM} / \mathrm{OPN}-\mathrm{a}$ had a slower growth rate than cells treated with medium collected from empty vector controls (VC). Treatment with CM containing OPN-b or OPN-c had little or no effect on CL1-5 cell growth (Figure 2B). We also conducted the same experiment in A549 cells. Unexpectedly, A549 CM/OPN-a did not inhibit growth in A549 cells (Figure 2C). It is possible that overexpression of OPN-a induces the secretion of different molecules in CL1-5 and A549 cells, causing different cell growth responses. Alternatively, this discrepancy in the effect of OPN-a on growth in CL1-5 and A549 cells may be explained by differences in receptor or down-stream effector expression levels. Thus, CL1-5 and A549 cells were treated with CM collected from CL1-5 (Figure 2D) or A549 (Figure 2E) cells expressing different OPN

A
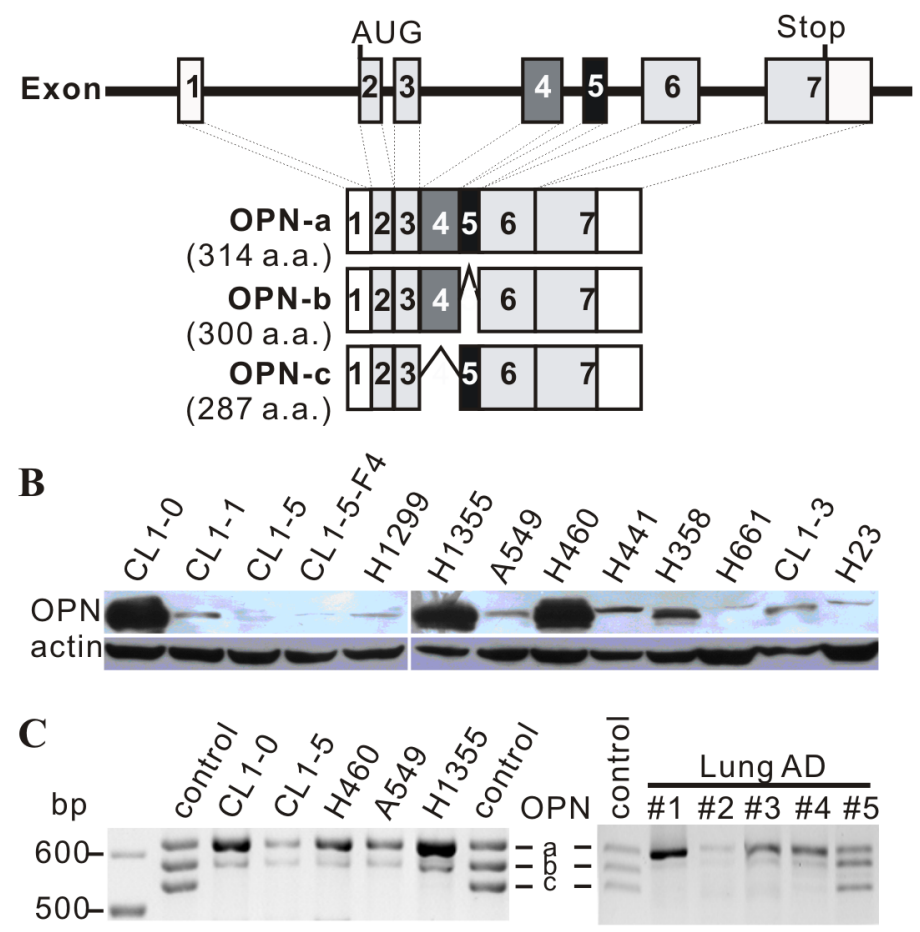

Figure 1: OPN expression in cell lines. A. Schematic diagram of OPN isoforms. OPN-a is the full-length isoform (314 a.a.), OPN-b lacks exon 5 (300 a.a.), and OPN-c is missing exon 4 (287 a.a.). B. Twenty $\mu$ g of total protein were subjected to Western blot analysis. OPN expression was low in several highly-invasive cell lines, including CL1-5, CL1-5-F4, H1299, and A549. C. Expression of OPN isoforms in various lung cancer cell lines and lung adenocarcinoma (AD) specimens. Control bands were mixed isoforms amplified from OPN-a, OPN-b, and OPN-c constructs via PCR. 
splicing variants. CM/OPN-a from either CL1-5 or A549 cells suppressed CL1-5, but not A549, cell growth.

Next, we screened CL1-5 cells stably expressing OPN-a with G418 (Figure 2F) and performed focus formation assays and cell growth analysis on the OPNstable clones. In agreement with $\mathrm{CM}$ treatment results, CL1-5 cells stably expressing OPN-a generated fewer and smaller foci compared to VC cells (Figure 2F). In addition, growth rates were lower in CL1-5 cells ectopically expressing OPN-a (Figure $2 \mathrm{G}$ ).

To further confirm that OPN-a directly suppresses CL1-5 cell growth, we used Ni-NTA to purify OPN-a from CM (Figure 3A). As shown in Figure $3 \mathrm{~B}$ and $3 \mathrm{C}$, purified OPN-a efficiently suppressed CL1-5, but not A549, cell growth. Collectively, these results demonstrated that OPN-a, but not OPN-b or OPN-c, had the ability to inhibit
A
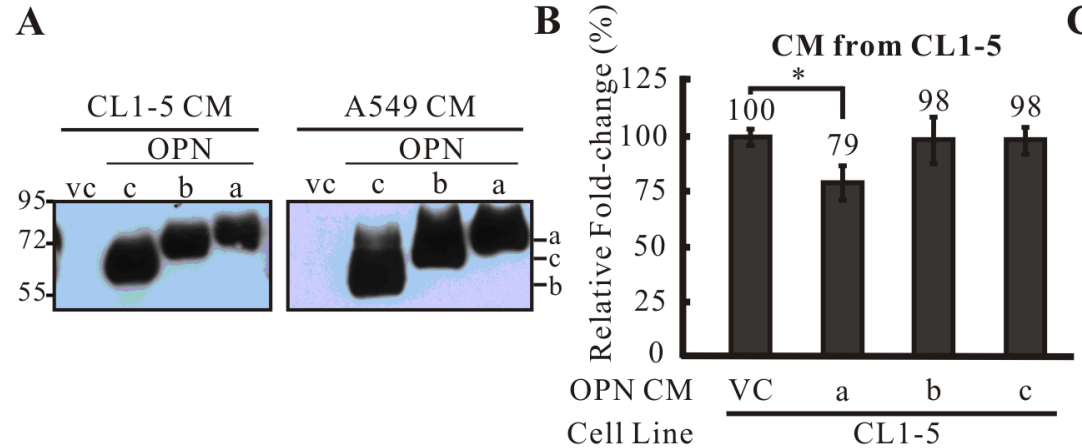

C

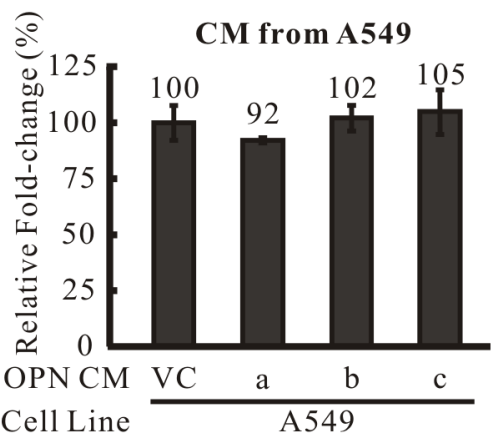

D

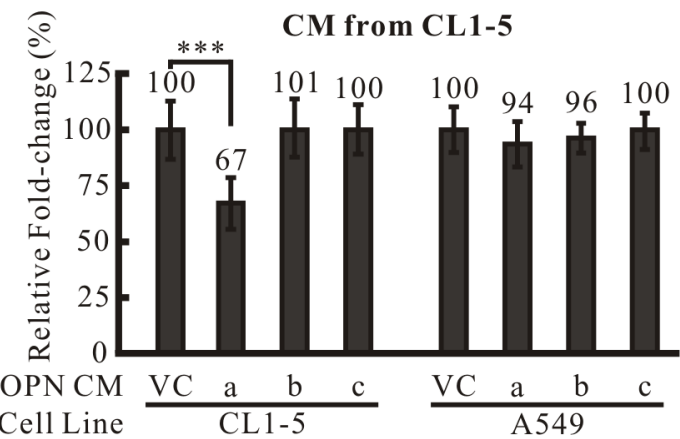

$\mathbf{F}$



E

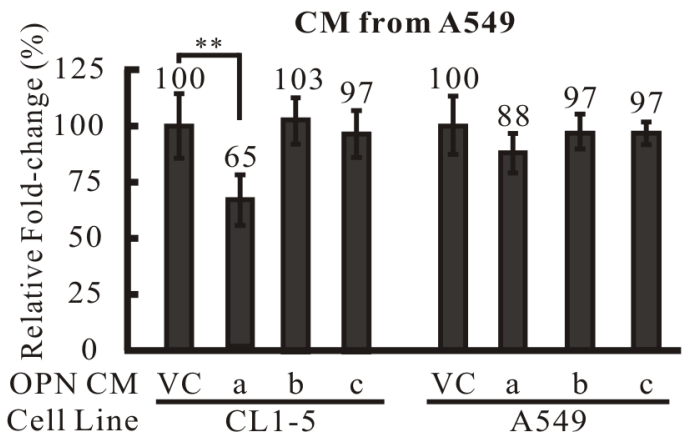

G

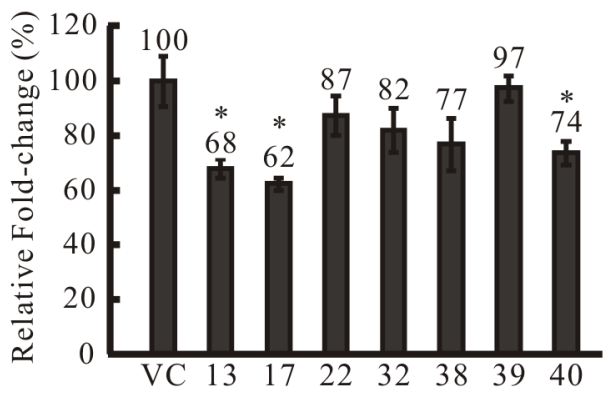

Figure 2: The effect of OPN-a on cell growth. A. Overexpressed OPN splicing variants were secreted into medium (CM) at similar levels. VC represents cells transfected with empty vector. B. CM from CL1-5 cells transiently transfected with various OPN splicing variants or $\mathrm{VC}$ was used to treat other CL1-5 cells. CM/OPN-a strongly inhibited CL1-5 cell growth, while CM containing OPN-b or OPN-c had little or no effect. Fold-changes in cell numbers were determined by dividing cell numbers at $24 \mathrm{~h}$ by those at $0 \mathrm{~h}$. Relative fold-change in cell number was calculated by dividing each fold-change in CM/OPN treatment cells by the fold-change in CM/VC cells. *, $p<0.05$. C. CM collected from A549 cells transiently transfected with various OPN splicing variants or VC was used to treat other A549 cells. In contrast to CL1-5 cells, CM containing OPN-a, OPN-b, or OPN-c did not inhibit A549 cell growth. D. CM containing various OPN splicing variants was collected from CL1-5 cells and used to treat CL1-5 and A549 cells. CM/OPN-a from CL1-5 cells inhibited growth of CL1-5, but not A549, cells. ***, $p<0.001$. E. CM containing various OPN splicing variants was collected from A549 cells and used to treat CL1-5 and A549 cells. CM/OPN-a from A549 cells inhibited growth of CL1-5, but not A549, cells. **, $p<0.01$. F. Expression of exogenous OPN-a in CL1-5 stable clones. All CL1-5/OPN-a stable clones showed low focus formation capacity compared to vector controls (VC). G. CL1-5 stable clones overexpressing OPN-a showed slower growth rates compared to VC. ${ }^{*}, p<0.05$. 
cell growth. However, OPN-a did not suppress growth in all lung cancer cells.

\section{ITGß3 is involved in OPN-a mediated growth inhibition}

Secreted OPN can bind to various integrins and CD44 to activate signaling pathways. We thus performed real-time PCR to detect differences in the expression of integrins and CD44 in CL1-5 and A549 cells. As shown in Figure 4A, most detectable integrins and CD44 variants were more highly expressed in A549 cells; however, the expression of integrins $\alpha 4, \alpha 5$, and $\beta 3$ was higher in CL1-5 cells. Among these three integrins, the disparity in $\beta 3$ expression was greatest between the two cell types. To determine whether ITG $\beta 3$ plays a role in OPN-a-induced inhibition of CL1-5 cell growth, we reduced ITG $\beta 3$ expression in CL1-5/OPN-a and CL1$5 / \mathrm{VC}$ stable clones and monitored their growth rates. Knockdown of ITG $\beta 3$ expression enhanced growth in the CL1-5/OPN-a stable clone (Figure 4B, solid lines). Similarly, CL1-5 parental cells with reduced ITG $\beta 3$ expression that were treated with purified OPN-a grew faster than CL1-5 parental cells with normal ITG $\beta 3$ expression after the same treatment (Figure 4D). OPN-a also inhibited growth in A549 cells overexpressing ITG $\beta 3$ (Figure 4E). Furthermore, OPN-a-induced growth inhibition was also observed in H460 and H1299 cells overexpressing ITG $\beta 3$ (Figure 4G). These results demonstrated that ITG $\beta 3$ is necessary for OPN-a-induced growth inhibition. In the absence of OPN-a, ITG $\beta 3$ was essential for growth in CL1-5 cells (Figures 4B). The efficacy of si-ITG $\beta 3$ in CL1-5 cells and ectopic ITG $\beta 3$ expression are shown in Figure 4F.

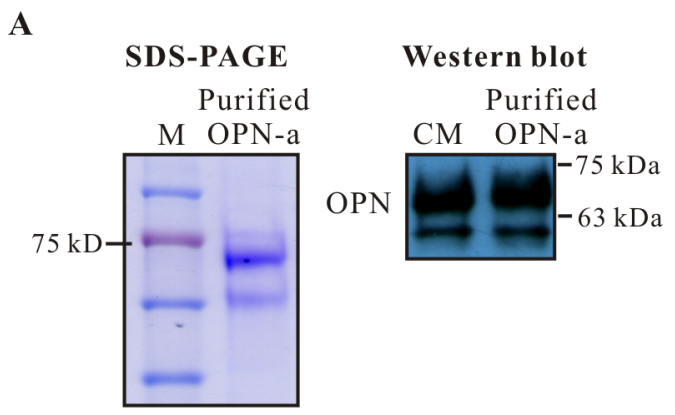

B

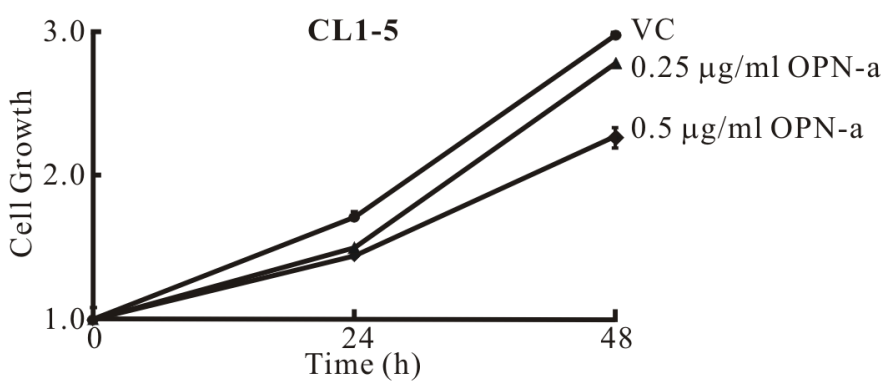

C

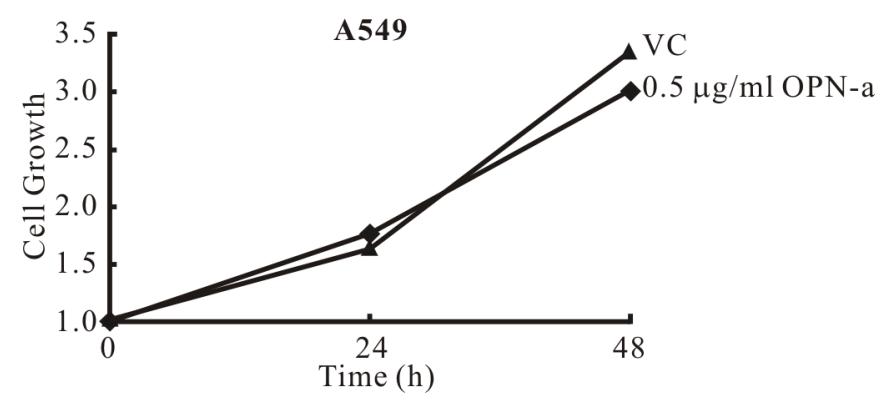

Figure 3: Purified OPN-a inhibits growth in CL1-5, but not A549, cells. A. OPN-a-Myc-His fusion protein was purified with Ni-NTA agarose. Left panel, $10 \mu \mathrm{g}$ of purified OPN-a were loaded. Right panel, Western blot analysis of purified OPN-a (3 $\mu \mathrm{g})$ and CM/ OPN-a $(50 \mu \mathrm{L})$ detected with anti-OPN antibody (O17). B. Purified OPN-a reduced CL1-5 cancer cell growth. VC represents treatment of material from the control CL1-5/Vector stable clone using the same purification process. C. Purified OPN-a did not affect A549 cell growth. 
A

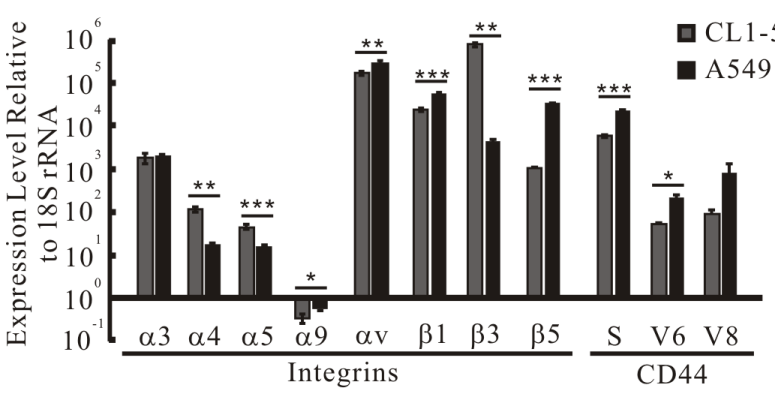

B

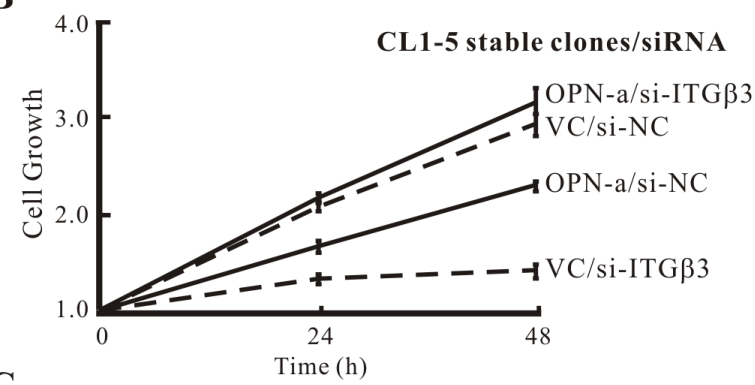

C

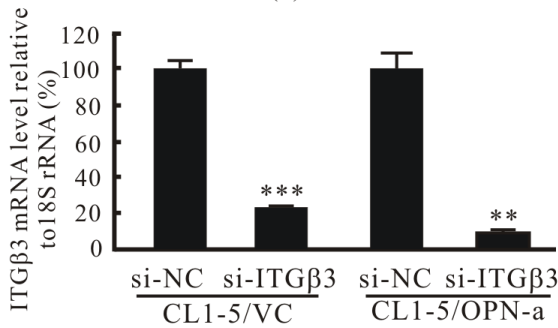

G
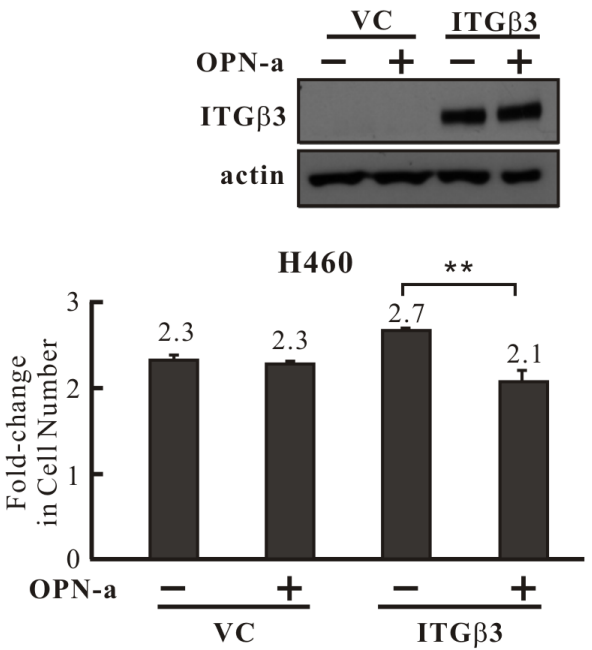

D

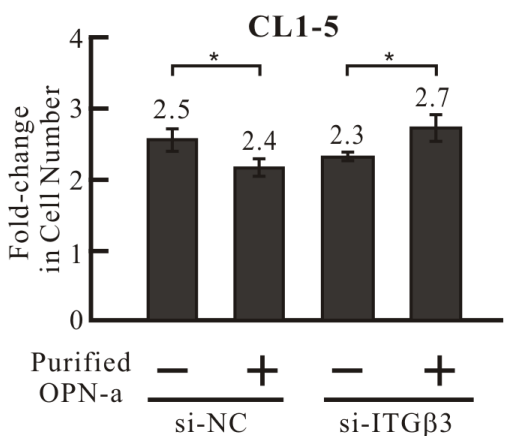

E

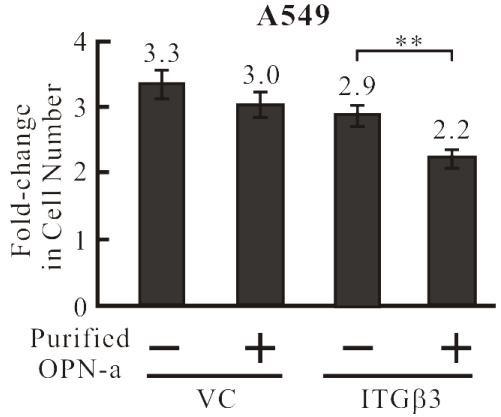

F

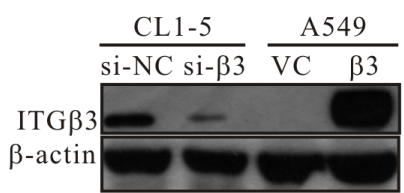

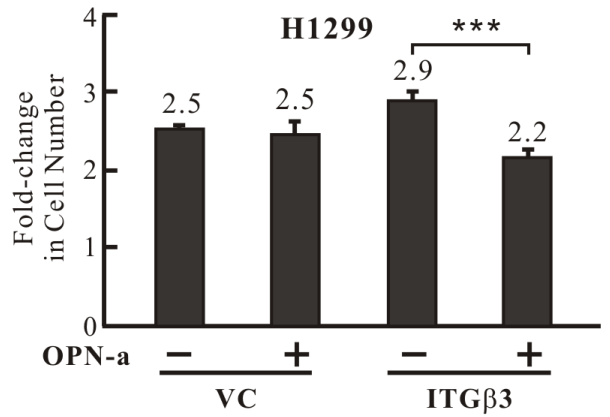

Figure 4: ITGß3 is necessary for OPN-a-induced growth inhibition. A. The expression of various integrin and CD44 isoform mRNAs was assessed by RT real-time PCR. Integrin $\alpha 4, \alpha 5$, and $\beta 3$ expression levels were lower in A549 cells than in CL1-5 cells. The difference in ITG 33 expression between CL1-5 and A549 cells was the most significant. *, $p<0.05 ; * *, p<0.01, * * *, p<0.001$. B. Growth curves for OPN-a stably-expressing CL1-5 cells treated with si-ITG $\beta 3$ or si-NC. The OPN-a stable clone (OPN-a/si-NC) grew more slowly than VC/si-NC cells. ITG $\beta 3$ knockdown reversed OPN-a-induced growth inhibition in CL1-5 cells (OPN-a/si-ITG $\beta 3$ ). ITG $\beta 3$ also increased growth in CL1-5 cells (comparison between VC/si-NC and VC/si-ITG 33 ). C. The efficacy of si-ITG 33 in the CL1-5/OPN-a stable clone was measured by RT real-time PCR in cells in (B). ${ }^{* *}, p<0.01, * * *, p<0.001$. D. CL1-5 cells transfected with si-ITG 33 or si-NC were treated with purified OPN-a. Similar to ITG $\beta 3$ knockdown in the CL1-5/OPN-a stable clone (B), ITG $\beta 3$ knockdown in CL15 cells reversed OPN-a-induced growth inhibition. ${ }^{*}, p<0.05$. E. A549 cells exogenously expressing ITG $\beta 3$ were treated with purified OPN-a. Overexpression of ITG $\beta 3$ in greatly reduced A549 cell growth, suggesting that ITG $\beta 3$ is required for OPN-a-induced growth inhibition. ${ }^{* *}, p<0.01$. F. The expression of ITG $\beta 3$ protein in CL1-5/si-ITG $\beta 3$ and A549/ITG $\beta 3$ cells in (D \& E). G. Purified OPN-a inhibited growth in H460/ITG $\beta 3$ and H1299/ITG 33 cells, but did not affect growth in H460 and H1299 cells. 


\section{In the absence of ITG $\beta 3$, OPN-a induces cell growth via the CD44/NFkB pathway}

In the absence of ITG $\beta 3$, OPN-a enhanced CL15 cell growth (Figure 4B \& 4D). Since OPN binds to various integrins and $\mathrm{CD} 44$, it is conceivable that $\mathrm{OPN}-\mathrm{a}$ could bind to another receptor to enhance growth in the absence of ITG 33 . We thus treated CL1-5/OPN-a and CL1-5/VC stable clones transfected with si-ITG $\beta 3$ with various signaling pathway inhibitors to screen for pathways involved in OPN-a-induced growth in the absence of ITG $\beta 3$. Inhibition of NFKB activity with Bay11-7082 blocked OPN-a-induced growth (Figure 5A). To confirm this result, we treated CL1-5/OPN-a and CL1-5/ VC stable clones transiently transfected with si-ITG $\beta 3$ or si-NC with Bay-11-7082 and measured cell growth. As shown in Figure 5B, ITG 33 knockdown in the CL1-5/ OPN-a stable clone enhanced cell growth (lanes $5 \& 7$ ). However, treatment with $10 \mathrm{nM}$ Bay-11-7082 inhibited OPN-a-induced growth in CL1-5/si-ITG 33 cells (Figure 5B, lanes $7 \& 8$ ), but did not inhibit growth in CL1-5/VC cells regardless of ITG $\beta 3$ expression (Figure 5B, lanes 1 $\& 2$; lanes 3 \& 4). Knockdown of both ITG $\beta 3$ and NFkB subunit p65 blocked OPN-a-induced growth in CL1-5 cells (Figure 5C, lanes $5 \&$ 6) compared to CL1-5 cells with ITG $\beta 3$ knockdown alone (lanes $3 \& 4$ ). The efficacies of si-ITG $\beta 3$ and si-p65 are shown in Figure 5D.

$\mathrm{NF} \kappa \mathrm{B}$ is the down-stream effector of CD44 [26]. To determine whether OPN-a promotes growth by binding to CD44 in the absence of ITG $\beta 3$, we blocked CD44 expression in CL1-5/si-ITG $\beta 3$ cells using RNAi (Figure $5 \mathrm{E}$ ) and examined the effect of OPN-a on growth. ITG $\beta 3$ and CD44 double knockdown inhibited OPN-a-induced cell growth (Figure 5F, lanes $5 \& 6$ ) compared to cells with ITG $\beta 3$ knockdown alone (Figure 5F, lanes 3 \& 4), suggesting that, when ITG $\beta 3$ expression is reduced, OPN-a instead binds to the CD44 receptor and enhances cell growth via the NFאB signaling pathway. This OPNa-induced growth did not occur following knockdown of both CD44 and ITG 33 . To confirm these observations, the effect of OPN-a on CL1-5/si-ITG $\beta 3$ cell growth when an anti-CD44 antibody was used to block CD44 function was determined. Anti-CD44 reduced OPN-a-induced growth in the absence of integrin $\beta 3$ (Figure $5 \mathrm{G}$, lanes $3 \& 4$ and 5 \& 6).

To investigate the effect of OPN-a on surface ITG $\beta 3$ expression, untreated CL1-5 cells and cells treated with $0.5 \mu \mathrm{g} / \mathrm{mL}$ purified OPN-a were immunostained with anti-ITG $\beta 3$. ITG $\beta 3$ staining appeared as punctuated fluorescence signals in the basal sections of confocal images of untreated CL1-5 cells. However, OPN-a treatment greatly reduced the punctuated and overall ITG $\beta 3$ signals (Figure 6A). Consistent with this finding, CL1-5 cells overexpressing OPN-a had lower ITG $\beta 3$ levels (Figure 6B). Furthermore, OPN-a treatment reduced the phosphorylation of FAK, the downstream effector of integrin, suggesting that $\mathrm{OPN}-\mathrm{a}$ treatment attenuated ITG $\beta 3$ activity (Figure 6C). When ITG $\beta 3$ was present, OPN-a did not affect the membrane distribution of CD44. However, following knockdown of ITG $\beta 3$ expression via si-RNA, OPN-a treatment increased membrane CD44 levels (Figure 6D). Indeed, co-immunoprecipitation of OPN-a with CD44 was increased in the CL1-5/OPN-a stable clone compared to the CL1-5/VC clone (Figure $6 \mathrm{~F}$ ). These results suggest that binding of OPN-a to ITG $\beta 3$ decreases ITG $\beta 3$ levels at focus adhesion points or focal adhesion formation. When ITG $\beta 3$ levels were reduced, OPN-a bound to, stabilized, and activated the membranelocalized alternative receptor CD44. Thus, CD44, ITG 33 , and OPN-a interact with each other to affect CL1-5 cell growth.

\section{DISCUSSION}

The results of this study showed that OPN-a can either increase or inhibit growth in cancer cells depending on the expression of its receptors. Levels of ITG $\beta 3$ and CD44 specifically determine the effects of OPN-a on growth in lung cancer cells. CL1-5 cells express high levels of ITG $\beta 3$, while A549 cells express low levels of ITG $\beta 3$. Both of these cell types express CD44, but CD44 levels are higher in A549 cells. OPN-a treatment reduced growth in CL1-5, A549/ITG 33 , H460/ITG 33 , and H1299/ ITG $\beta 3$ cells compared to untreated cells. These results suggest that ITG $\beta 3$ is necessary for OPN-a-induced growth inhibition. Immunostaining revealed that OPN-a treatment greatly diminished membrane and overall ITG $\beta 3$ levels. It is possible that the binding of OPN-a to ITG $\beta 3$ causes internalization and destabilization of ITG $\beta 3$ as well as other associated growth receptors.

Knockdown of ITG 33 expression in CL1-5 cells not only abolished OPN-a-induced growth inhibition, but also enhanced OPN-a-induced cell growth. In the absence of ITG $\beta 3$, OPN-a increased cell growth via the CD44/NFkB pathway. In line with this result, OPN-a treatment greatly enhanced membrane CD44 levels following si-RNA-induced ITG $\beta 3$ knockdown. Based on these results, we propose that, in the absence of OPN-a, ITG $\beta 3$ increases growth by binding to a growth factor or activating a growth receptor (Figure 7A). Increased $\mathrm{OPN}-\mathrm{a}$ levels in the surrounding environment block the binding of ITG $\beta 3$ to growth factors, thus reducing cell growth. Alternatively, binding of OPN-a to ITG $\beta 3$ might result in the internalization of ITG $\beta 3$ as well as associated growth receptors, thus inhibiting cell growth. (Figure 7C). In contrast, when ITG $\beta 3$ levels are low, OPN-a binds to, stabilizes, and activates CD44, which in turn activates growth signals (Figure 7D). Finally, in the absence of OPN-a, ITG $\beta 3$ is essential for CL1-5 cell growth (Figure 7B).

OPN mediates cell migration through various integrins, including $\alpha v \beta 1, \alpha v \beta 3, \alpha v \beta 5, \alpha 4 \beta 1, \alpha 5 \beta 1$, 

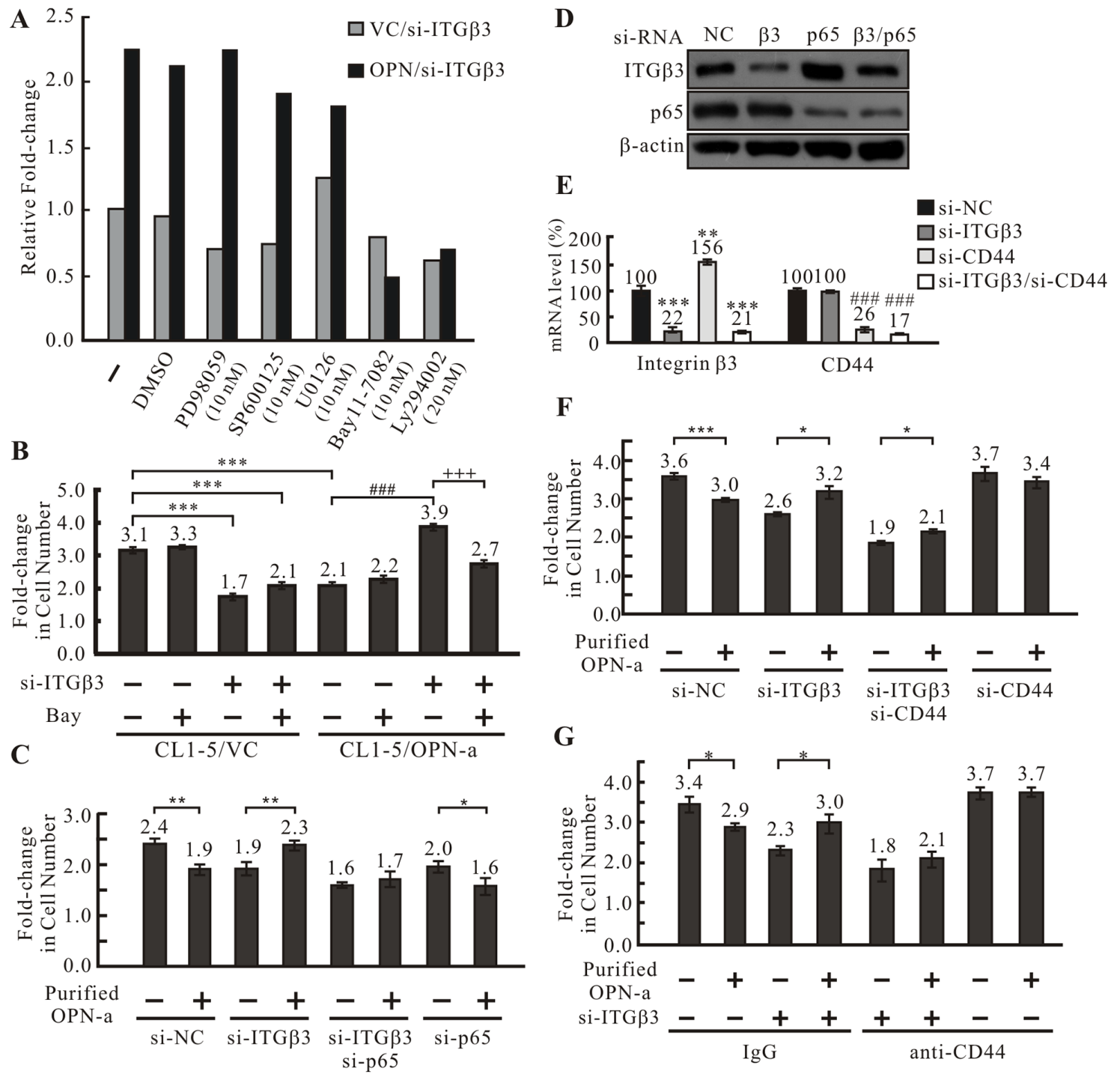

Figure 5: OPN-a induces cell growth following knockdown of ITGß3 via the CD44/NFkB pathway. A. Screening of pathways involved in OPN-a-induced growth inhibition. OPN-a stably expressing or empty vector CL1-5 cells were transiently transfected with si-ITG $\beta 3$ and treated with various pathway inhibitors. Fold-changes in cell numbers were determined by dividing cell numbers at $48 \mathrm{~h}$ by those at $0 \mathrm{~h}$. Relative fold-change in cell number was calculated by dividing each fold-change in OPN/si-ITG $\beta 3$ cells by the foldchange in VC/si-ITG 33 cells for each inhibitor treatment. NFאB inhibitor Bay11-7082 greatly inhibited growth in CL1-5/OPN-a cells with RNAi-induced ITG33 knockdown. PD98059: MAPK inhibitor; SP600125: JNK inhibitor; U0126: MEKK inhibitor; LY294002: PI3K inhibitor. B. The involvement of NFKB in OPN-a-induced growth inhibition. CL1-5/OPN-a and CL1-5/VC stable clones were transfected with si-ITG 33 or si-NC and treated with/without $10 \mathrm{nM}$ Bay11-7082 for $48 \mathrm{~h}$. Ectopic expression of OPN-a reduced cell growth (lanes 1 \& 5). ITG 33 knockdown not only blocked OPN-a-induced growth inhibition, but also increased CL1-5/OPN-a cell growth (lanes 5 \& 7). Bay11-7082 treatment abolished this increase in growth (lanes $7 \& 8)$. Cell numbers were counted before $(0 \mathrm{~h})$ and after $(48 \mathrm{~h})$ treatment to calculate the fold-change in cell numbers. ${ }^{* * *}, p<0.001 ;{ }^{\# \#}, p<0.001 ;^{+++}, p<0.001$. C. The involvement of p65 in OPN-a-induced growth inhibition. CL1-5 cells were treated with si-ITG 33 , si-p65, or si-ITG $\beta 3 / \mathrm{si}$-p65 and incubated with/without $0.5 \mu \mathrm{g} / \mathrm{mL}$ purified OPN-a for $24 \mathrm{hr}$. Purified OPN-a inhibited growth in CL1-5/si-NC cells (lanes 1 \& 2). Following ITG 33 knockdown, OPN-a increased, rather than inhibited, cell growth (lanes $1 \& 2$ and lanes $3 \& 4$ ). siRNA-induced knockdown of both ITG 33 and p65 eliminated this increase in growth (lanes $3 \& 4$ and $5 \& 6$ ), indicating that NFKB is required for OPN-a-induced increases in growth in CL1-5/si-ITG $\beta 3$ cells. The fold-change in cell number was calculated using cell numbers counted before and after OPN-a treatment $*, p<0.05$; $* *, p<0.01$. D. The efficacy of si-ITGß3 (5 pmol) and si-p65 (50 pmol) measured by Western blot analysis in the cells in (C). E. Efficiency of si-ITGß3 (5 pmol) and siCD44 (25 pmol) knockdown in CL1-5 cells in (F) measured by RT real time PCR. **, $p<0.01 ; * * *, p<0.001$; \#\#\#, $p<0.001$. F. CD44 knockdown abolished OPN-a-induced increases in growth in CL1-5/si-ITG 33 cells. Purified OPN-a inhibited growth in CL1-5 cells (lanes 1 \& 2), and ITG 33 knockdown enhanced cell growth (lanes $3 \& 4$ ). CD44 knockdown reduced this increase in cell growth (lanes $3 \& 4$ and lanes $5 \& 6$ ). The fold-change in cell number was calculated using cell numbers counted before and after OPN-a treatment. *, $p<0.05$; $* *, p<0.01 ; * * *, p<0.001$. G. ITG 33 knockdown in CL1-5 cells not only abolished OPN-a-induced growth inhibition, but also increased cell growth (lanes $1 \& 2$ and lanes $3 \& 4$ ). Blocking CD44 with $0.5 \mu \mathrm{g}$ of CD44 antibody reduced the OPN-a-induced increase in growth in CL1-5/si-ITGß3 cells (lanes $3 \& 4$ and $5 \& 6$ ). IgG is the negative control for the CD44 antibody. *, $p<0.05$. 
$\alpha 8 \beta 1$, and $\alpha 9 \beta 1$ (reviewed in [13]). Among integrin heterodimers, $\alpha v \beta 3$ is most commonly associated with OPN-induced malignancy. The $\alpha v \beta 3$ complex is involved in OPN-induced migration and invasion in tumor cells $[27,28]$, as well as OPN-induced endothelial cell migration and angiogenesis [29, 30]. In addition, ligation of OPN to CD44 increases cell adhesion, invasion, and transformation [13, 31]. OPN directly interacts with integrin $\beta 3$ and CD44 [32, 33]; the RGD and SVVYGLR sequences in OPN are responsible for its interaction with integrin [34], while CD44 binding sites in the OPN sequence have not yet been identified. Interestingly, OPN acts as a bridge molecule between CD44 variants and integrins to stimulate motility in murine cells [5]. The interaction between OPN and $\alpha v \beta 3$ increases CD44v6 expression in HepG2 cells and enhances cell adhesion to hyaluronic acid [35]. Additionally, binding of OPN-a to CD44 variants activates integrins through Src, thus promoting ECM-derived survival signals in gastric cancer [36].

Although up-regulation of OPN in plasma or cancer tissues is associated with poor cancer prognosis, our results clearly demonstrate that OPN-a, but not OPN-b or -c, decreased CL1-5 cell growth. The reason for which OPN-a overexpression suppresses growth in these cancer cells is unknown. OPN promotes the migration of immune cells toward a wound site. However, tumor-derived OPN has been shown to inhibit macrophage function and promote tumor growth [37]. The ability of tumor cells to evade host immunity may result from decreased NO production by macrophages in response to tumor-derived OPN [38]. The effects of different OPN isoforms on immunity are also unknown. The OPN-a splicing variant, which was the most highly expressed in tumor cells, may
A

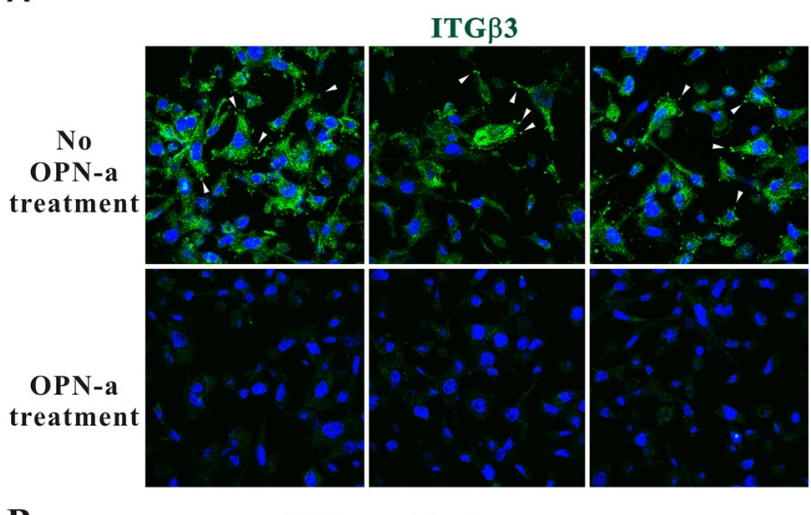

B

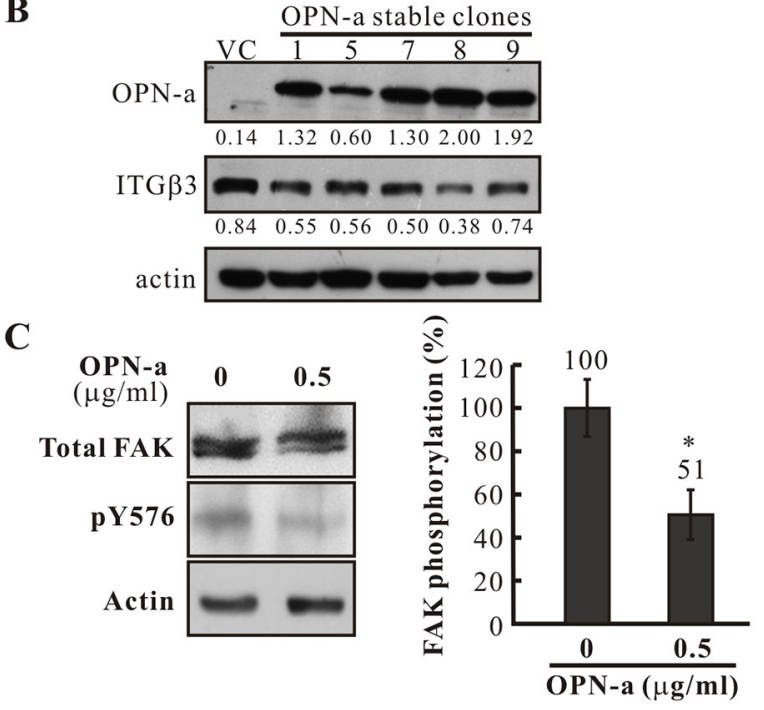

D

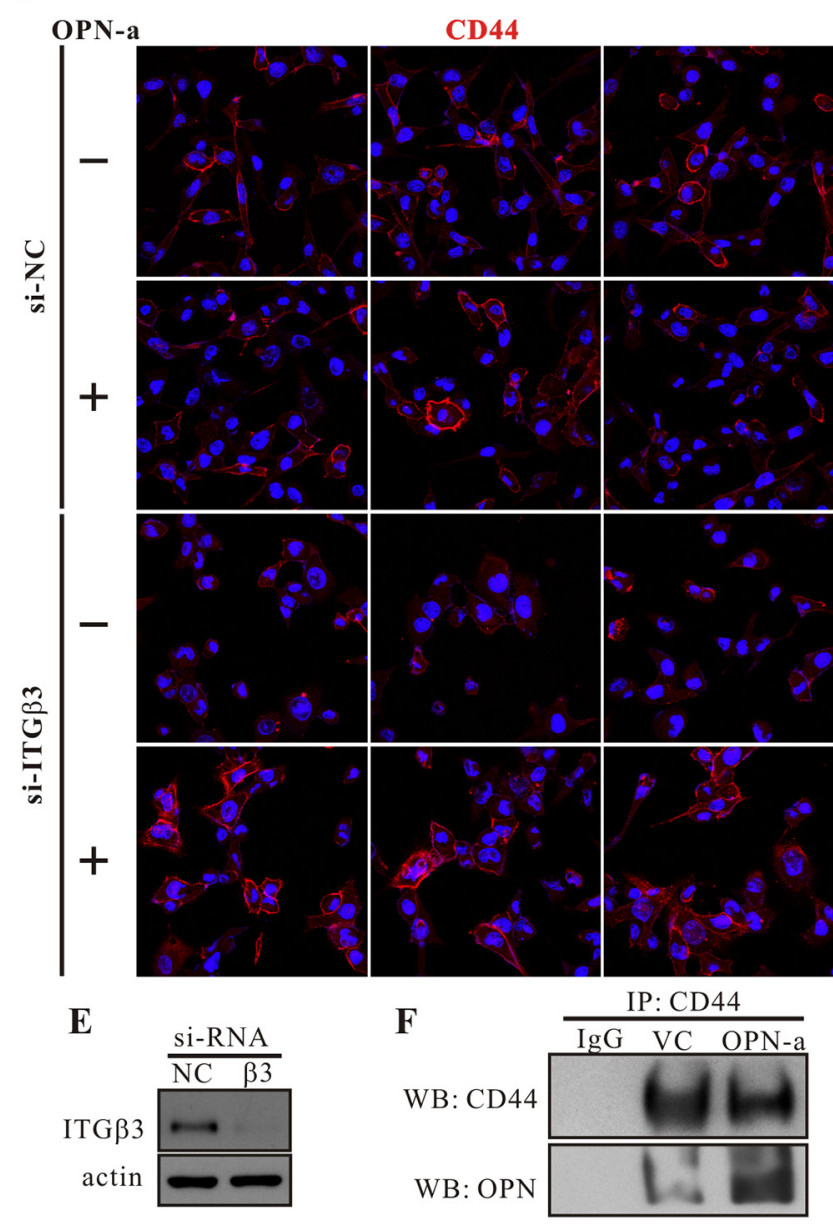

Figure 6: The effects of OPN-a on ITG 33 and CD44 membrane distribution in CL1-5 cells. A. CL1-5 cells were treated with/without OPN-a and immunostained with anti-ITG $\beta 3$ antibody. ITG $\beta 3$ staining appeared as punctuated signals (arrow heads) in the basal section of confocal images in untreated cells; OPN-a treatment greatly decreased both punctuated and overall signals. B. Expression of ITG $\beta 3$ was reduced in OPN-a stably transfected cells in Western blot analysis. C. FAK Y576 phosphorylation was decreased in CL1-5 cells treated with $0.5 \mu \mathrm{g} / \mathrm{mL}$ of purified OPN-a compared to untreated cells. ${ }^{*}, p<0.05$. D. CL1-5 cells treated with/without si-ITG $\beta 3$ were incubated with/without purified OPN-a. Cells were then immunostained with anti-CD44. When ITG $\beta 3$ expression was reduced, purified OPN-a increased membrane-localized CD44 levels. E. The efficacy of si-ITG $\beta 3$ in cells in (D). F. Increased co-immunoprecipitation of OPN-a with CD44 was observed in the CL1-5/OPN-a stable clone compared to the CL1-5/VC clone. 
In the Absence of OPN-a

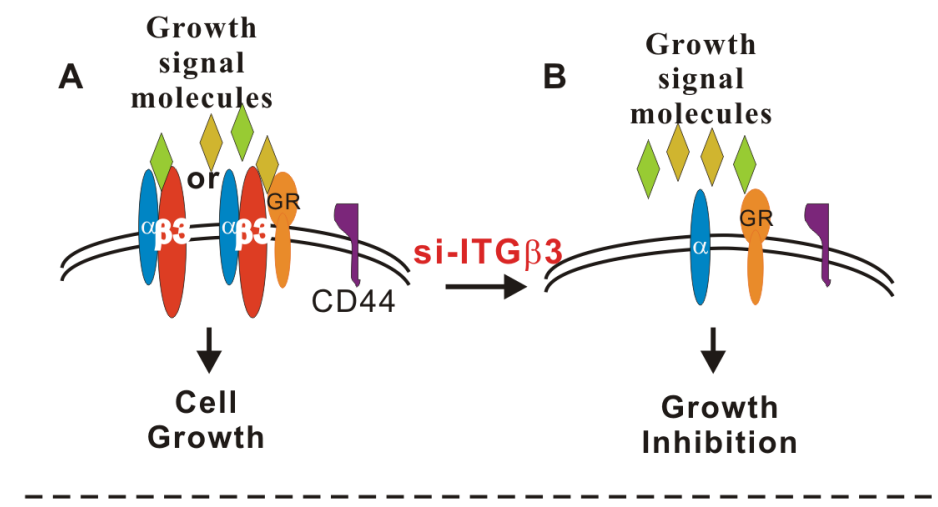

In the Presence of OPN-a

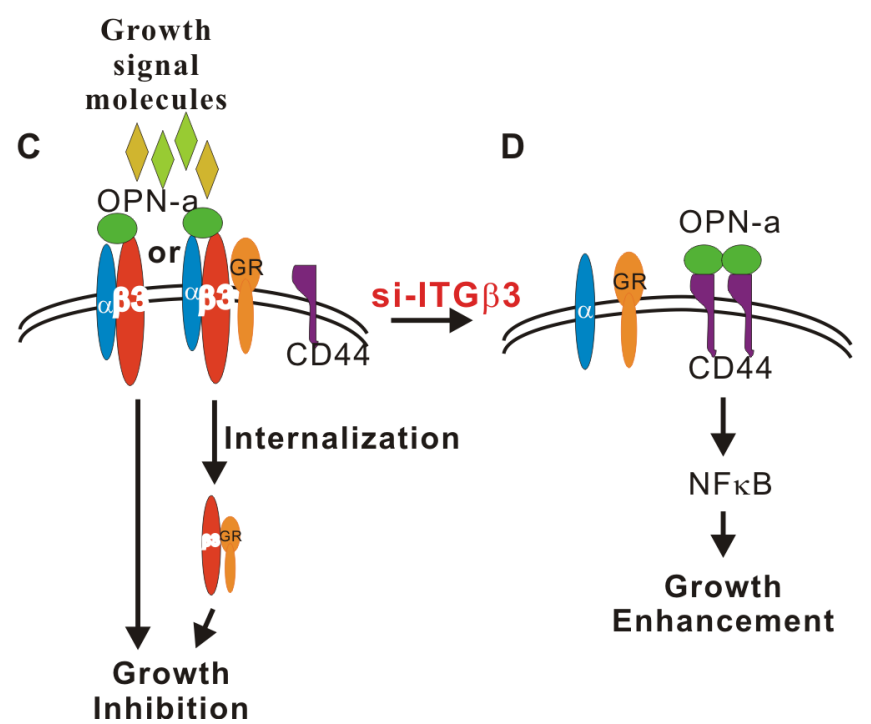

Figure 7: Schematic diagram of OPN-a- and ITG $\beta 3$-mediated growth regulation. A. In the absence of OPN-a, ITG 33 binds to a signaling molecule (growth signal, environmental molecule or growth receptor) to maintain growth in CL1-5 cells. B. Knockdown of ITG $\beta 3$ reduces cell growth. C. OPN-a might compete with growth signal molecules to bind ITG $\beta 3$ or cause internalization of ITG $\beta 3$ or the ITG $\beta 3$ /growth receptor complex, thus reducing cell growth. D. Knockdown of ITG $\beta 3$ enables OPN-a to bind to the alternate receptor CD44, which increases CD44 membrane localization and increases growth by activating NFkB.

help to inhibit immune surveillance. In addition, we found that $\mathrm{OPN}-\mathrm{a}$ treated fibroblasts may secrete molecules that enhance lung cancer cell growth. (data not shown)

Our study revealed that ITG $\beta 3$ and CD44 expression levels determine whether OPN-a inhibits or enhances growth in lung cancer cells. Furthermore, the effect of ITG $\beta 3$ on cancer cell growth is determined by environmental levels of OPN. OPN and ITG $\beta 3$ are attractive targets for cancer therapy, and ITG $\beta 3$ target therapy (such as cyclic RGD) has been widely investigated. Our study suggests that ITG $\beta 3$ target therapy would effectively inhibit the growth of OPNnegative cells, but may also increase the growth of OPN-positive cells.

\section{MATERIALS AND METHODS}

\section{Cell culture and treatment}

The NCI-A549, NCI-H23, NCI-H441, and NCI-H1355 lung adenocarcinoma (AD) cell lines, NCI-H358 and NCI-H1299 non-small cell lung cancer (NSCLC), and NCI-H460, NCI-H661 large cell lung carcinoma cell lines were obtained from the Bioresource Collection and Research Center (BCRC, Taiwan). CL1-0, CL1-3, and CL1-5 lung AD cell lines were kindly provided by Dr. P-C Yang (Department of Internal Medicine, National Taiwan University, Taipei, Taiwan). For cell growth assay, A549 and H1299 cells 
were maintained in DMEM medium containing 10\% fetal bovine serum (FBS). CL1-0, CL1-5, and H460 cells were maintained in RPMI1640 containing 10\% FBS. RPMI, DMEM and FBS were purchased from Gibco.

\section{Cloning and transfection}

$O P N-a$ and $-b$ were PCR amplified from CL1-0 cDNA and cloned into pcDNA ${ }^{\mathrm{TM}} 3.1 /$ myc-His(-)A vectors. To obtain OPN-c, PCR-based site-directed mutagenesis was carried out to delete exon 4 in the OPN-a construct. ITG $\beta 3$ was PCR amplified (forward primer: 5'-GCGACGGTCCGGCCACC ATGCGAGCGCGG-3'; reverse primer: 5'-GCCACGGAC CGCAGTGCCCCTGTACGTGAT-3') from CL1-5 cDNA and ligated with a T/A vector. After sequencing, ITG $\beta 3$ was subcloned into the RsrII site in pcDNA 3.1/myc-His(-)A. The pcDNA vector was engineered by inserting an adaptor with a RsrII restriction site (F' oligo: 5'-GATCCGGTCCGCAC-3'; R' oligo: 5'-GATCGTGCGGACCG-3') into the BamHI site and was mutated at the RsrII site in the $\mathrm{Neo}^{\mathrm{r}}$ gene. Transfection was performed with Lipofectamine ${ }^{\mathrm{TM}}$ 2000 (Invitrogen) transfection reagent according to the manufacturer's instructions. The transfected CL1-5 cells were treated with G418 (500 $\mu \mathrm{g} / \mathrm{mL})$ (Sigma-Aldrich) for 3-4 weeks to select stable clones. For RNA interference, siRNA (si-ITG $\beta 3$ : 5'-GGACUACGCUCUCUGAAUUTT-3', si-CD44: 5'-UAUUCCACGUGGAGAAAAATT-3', sip65: 5'-CCUUUCUCAUCCCAUCUUUTT-3', or si-NC: 5'-UUCUCCGAACGUGUCACGUTT-3' (provided by MDBio, Inc, Taiwan)) was transfected into cell lines using Lipofectamine, and cell lines were then cultured for $24 \mathrm{~h}$. The transfected cells were then transferred into appropriate media for analyses.

\section{Western blot analysis}

Cells were lysed with lysis buffer containing 0.5\% NP-40, 50 mM Tris-Cl (pH 7.5), 1 mM EDTA, and protease inhibitor cocktail (Roche) for $3 \mathrm{~min}$. Then, cell debris was removed by centrifugation and the protein concentration was determined using the Bradford protein assay kit (Bio-Rad). Equal amounts of protein were separated on sodium dodecyl sulfatepolyacrylamide (SDS-PAGE) gels and then transferred to polyvinylidene fluoride (PVDF) membranes (Perkin Elmer). After blocking, the membranes were incubated with anti-Flag (Sigma), anti-OPN (\#10A16 or \#O17, IBL10011, 18625.), anti-ITGß3 (Abcam ab75872), or anti-p65 antibodies (Millipore, 06-418) at $4^{\circ} \mathrm{C}$ overnight, followed by incubation with horseradish peroxidase-conjugated secondary antibody at room temperature for 1 hour. The blots were visualized using an enhanced chemiluminescence (ECL) kit (Perkin Elmer).

\section{Immunofluorescence staining}

CL1-5 cells $\left(3 \times 10^{5}\right.$ cells/well) were seeded onto 6-well plates and cultured to $70 \%$ confluence. Cells were then transfected with or without si-NC or si-ITG 33 using Lipofectamine and incubated for $24 \mathrm{~h}$. The transfected cells were seeded $\left(1.5 \times 10^{5}\right.$ cells $)$ onto cover slips. After 16 $\mathrm{h}$ incubation, cells were treated with $0.5 \mu \mathrm{g} / \mathrm{mL} \mathrm{OPN-a}$ for $24 \mathrm{~h}$. The cells were then fixed with $100 \%$ methanol for $10 \mathrm{~min}$ at $-20^{\circ} \mathrm{C}$, followed by blocking with $3 \%$ BSA for another $60 \mathrm{~min}$ at room temperature. The fixed cells were then probed with anti-integrin $\beta 3$ (1:200 dilution; Abcam ab75872) or CD44 (1:200 dilution; GeneTex Gtx102111) antibody for $1 \mathrm{~h}$ at room temperature, followed by incubation with a TRITC or F488-conjugated goat antirabbit IgG antibody (1:500 dilution; Sigma, St. Louis, $\mathrm{MO}, \mathrm{USA}$ ) for $1 \mathrm{~h}$ at room temperature. The cells were then washed with PBS three times, stained with DAPI for $15 \mathrm{~min}$, and mounted with mounting solution. The expression and location of target proteins were observed with a laser scanning confocal microscope.

\section{Immunoprecipitation}

For immunoprecipitation of CD44, 5x10 ${ }^{6}$ CL1-5/ OPN-a cells were lysed with RIPA buffer (50 mM Tris, $\mathrm{pH}$ 7.4, $150 \mathrm{mM} \mathrm{NaCl}, 1 \% \mathrm{NP}-40,1 \%$ sodium deoxycholate, $2 \mathrm{mM}$ EDTA 2, $1 \mathrm{mM}$ PMSF, protease inhibitor, and phosphatase inhibitor). The lysate (1 mg protein) was incubated with $4 \mu \mathrm{g}$ anti-CD44 (Abcam, ab157107) antibody overnight at $4^{\circ} \mathrm{C}$. Washed protein $\mathrm{G}$ beads $(50$ $\mu \mathrm{L}$, MagQu, MF-PRG-3000) were then added to the protein-antibody mixture followed by incubation for $5 \mathrm{~h}$ at $4^{\circ} \mathrm{C}$. After washing, the protein complex was recovered by heating at $95^{\circ} \mathrm{C}$ for $3 \mathrm{~min}$ in loading buffer. CD44 and OPN were resolved with SDS-PAGE and immunoblots were subsequently probed with anti-CD44 (Abcam ab157107) and anti-OPN (O17, IBL 18625) antibodies.

\section{Reverse transcription and real-time PCR}

Total RNA ( $2 \mu \mathrm{g})$ was extracted from tissues and cell lines with TRIZOL Reagent (Invitrogen), treated with RQ1 DNase (Promega \#M6101), and subjected to cDNA synthesis according to the manufacturer's instructions (Epicentre RT80125K). All real-time PCR reactions were carried out with the ABI StepOne system using FastStart Universal SYBR Green Master (ROX) (Roche). The following primers were used for real-time PCR: $18 S$ rRNA-F, 5'-TCGGAACTGAGGCCATGA-3' and $18 S$ rRNA-R, 5'-CCGGTCGGCATCGTTTA-3'. Primers for detection of OPN isoforms were as follows: 5'-CATCACCTGTGCCATACCA-3' (located at exon 2) and 5'-GGCTGTCCCAATCAGA-3' (located at exon 6). Primers for detection of integrins were as follows: 
ITG $\alpha 3$-F, 5'- TGCTCACCCCTCACTCCT-3'; ITG $\alpha 3$-R, 5'- GGCAGTCCCAGCTTCTCT-3'; ITG $\alpha 4$-F, 5' - GCT CGGGAGCAGTAATGAA-3'; ITG $\alpha 4$-R, 5' - ATCTGCA CGGCCATTGTA-3'; ITG $\alpha 5$-F, 5'- CCCTGCCGCTCAG ATTT-3'; ITG $\alpha 5$-R, 5'- CTGGCCTGGCGAGTCT-3'; ITG $\alpha v$-F, 5'- CAAAGCAAACACCACCCA-3'; ITG $\alpha$ 9-F, 5'- GTGATGCCGGTGGGATA-3'; ITG $\alpha$ 9-R, 5'- CCGGGAGGAAGATGGA-3'; ITG $\alpha v$-R, 5'-GGG GCACAGGCCAA-3'; ITG $\beta 1$-F, 5'-CGTAGCAAAG GAACAGCAGA-3'; ITG $\beta 1$-R, 5'- AGTCCGAAGTA ATCCTCCTCA-3'; ITG $\beta 3-\mathrm{F}, \quad 5$ '- GGCCCCTCA GCGACA-3'; ITG $\beta 3$-R, 5'- AATGCCCCGAAGCCA-3'; ITG $\beta 5$-F, 5'- TGGCTGGCGAAAGGAT-3'; ITG $\beta 5$-R, 5'- GCAAGGCAAGGGATGGAT-3'. Primers for detection of CD44 variants were as follows: CD44-F, 5'- TCTACCCCAGCAACCCTACT-3'; CD44-R, 5'CCACCTTCTTGACTCCCATGT-3'; CD44v6-F, 5' - TCC AGGCAACTCCTAGTAGTACA-3'; CD44v6-R, 5'- GGT GTGAGATTGGGTTGAA-3'; CD44v8-F， 5'- CGC TTCAGCCTACTGCAA-3'; CD44v8-R, 5'- GGGT CTCTTCTTCCACCTGT-3'.

\section{Cell growth assay}

Cells were cultured to $70 \%$ confluence. After detachment, $3 \times 10^{4}$ cells were seeded onto 12 -well plates and cultured in RPMI-1640 (for CL1-5) or DMEM (for A549) containing $10 \%$ FBS with or without CM or purified OPN-a. After $16 \mathrm{~h}$ of incubation, cells were harvested and viable cells were counted; this time point was designated as $0 \mathrm{~h}$. After an additional $24 \mathrm{~h}$ of incubation, cells were harvested and viable cells were counted; this time point was designated as $24 \mathrm{~h}$. For pathway inhibitor screening, $3 \times 10^{4}$ cells were inoculated and incubated for $16 \mathrm{~h}$. Cells were then either harvested before treatment (designated as $0 \mathrm{hr}$ ) or treated with various inhibitors for $48 \mathrm{~h}$ (designated $48 \mathrm{~h}$ ), and viable cells were counted. Fold-change in cell number was calculated by dividing viable cell numbers at $24 \mathrm{~h}$ (or $48 \mathrm{~h}$ ) by those at $0 \mathrm{~h}$. Relative fold-change in cell number was calculated by dividing each fold-change in treatment cells by the fold-change in control cells.

\section{Focus formation assay}

For the focus formation assay, 200 cells were seeded onto a $3.5 \mathrm{~cm}$ dish. Following incubation for 7-9 days, colonies were fixed with $100 \%$ ice-cold methanol for 30 min, followed by staining with $20 \%$ Giemsa for $30 \mathrm{~min}$.

\section{Purification of OPN-a from CM/OPN-a}

To purify ectopically expressed OPN-a, the CL15/OPN-a-Myc-His stable clone or CL1-5/VC cells were grown to $100 \%$ confluence in $10 \mathrm{~cm}$ dishes. The medium was replaced with $4 \mathrm{~mL}$ RPMI serum-free medium, followed by incubation at $37^{\circ} \mathrm{C}$ for $24 \mathrm{~h}$. About $120 \mathrm{~mL}$ of $\mathrm{CM}$ were collected and concentrated with a Vivaspin ${ }^{\circledR}$
15R Centrifugal Concentrator to about $5 \mathrm{~mL}$, followed by incubation with an equal volume of Ni-NTA agarose beads (QIAGEN) at $4^{\circ} \mathrm{C}$ for $2 \mathrm{~h}$. After washing with wash buffer $\left(50 \mathrm{mM} \mathrm{Na} \mathrm{HPO}_{4}, 300 \mathrm{mM} \mathrm{NaCl}, 20 \mathrm{mM}\right.$ imidazole, $0.05 \%$ Tween $20, \mathrm{pH} 8.0$ ), OPN-a was eluted with elution buffer $\left(50 \mathrm{mM} \mathrm{Na}_{2} \mathrm{HPO}_{4}, 300 \mathrm{mM} \mathrm{NaCl}, 250\right.$ $\mathrm{mM}$ imidazole, $0.05 \%$ Tween $20, \mathrm{pH} 8.0$ ). To eliminate imidazole, the eluent was dialyzed against 1xPBS. The purified OPN-a concentration was determined using a Bradford protein assay kit (Bio-Rad).

\section{Preparation of conditioned medium}

Conditioned medium (CM) was prepared from cells transiently or stably transfected with different OPN splicing variants. All cells were grown to full confluence in growth medium with $10 \%$ FBS, which was then replaced with $2 \mathrm{~mL}$ of fresh medium followed by incubation at $37^{\circ} \mathrm{C}$ for $24 \mathrm{~h}$ in $3.5 \mathrm{~cm}$ dishes. After removing cells debris by centrifugation, $\mathrm{CM}$ was mixed with equal volumes of fresh media containing 10\% FBS for cell culture assays.

\section{Statistical analysis}

All growth assays, except for the pathway inhibitor analysis experiment, were repeated independently at least times with three replicates in each experiment. Values are presented as mean \pm SD. GraphPad Prism 5.0 software (GraphPad Software, Inc., San Diego, CA, http://www. graphpad.com) was used for statistical analyses. Statistical significance was assessed by Student's $t$-tests and is indicated as follows: *, $p<0.05$; **, $p<0.01$; ***, $p<0.001$; \#\#, $p<0.001 ;{ }^{+++}, p<0.001$.

\section{ACKNOWLEDGMENTS}

We thank Dr. Jiunn-Liang Ko, Dr. Wen-Jun Wu, and Dr. Hui Lee for their expert consultation and advice and Jingyao Chang for financial support of this work.

\section{CONFLICTS OF INTEREST}

The authors declare no conflicts of interest.

\section{GRANT SUPPORT}

This work was supported by National Science Council grant NSC 102-2320-B-040-010-MY2 (Taiwan, R.O.C.) to Jinghua Tsai Chang.

\section{REFERENCES}

1. Senger DR, Wirth DF and Hynes RO. Transformed mammalian cells secrete specific proteins and phosphoproteins. Cell. 1979; 16:885-893. 
2. O'Regan A and Berman JS. Osteopontin: a key cytokine in cell-mediated and granulomatous inflammation. International journal of experimental pathology. 2000; 81:373-390

3. Yokosaki Y, Tanaka K, Higashikawa F, Yamashita K and Eboshida A. Distinct structural requirements for binding of the integrins alphavbeta6, alphavbeta3, alphavbeta5, alpha5beta1 and alpha9beta1 to osteopontin. Matrix Biol. 2005; 24:418-427.

4. Weber GF, Ashkar S, Glimcher MJ and Cantor H. Receptorligand interaction between CD44 and osteopontin (Eta-1). Science (New York, NY. 1996; 271:509-512.

5. Katagiri YU, Sleeman J, Fujii H, Herrlich P, Hotta H, Tanaka K, Chikuma S, Yagita H, Okumura K, Murakami M, Saiki I, Chambers AF and Uede T. CD44 variants but not CD44s cooperate with beta1-containing integrins to permit cells to bind to osteopontin independently of arginineglycine-aspartic acid, thereby stimulating cell motility and chemotaxis. Cancer research. 1999; 59:219-226.

6. Cui R, Takahashi F, Ohashi R, Gu T, Yoshioka M, Nishio K, Ohe Y, Tominaga S, Takagi Y, Sasaki S, Fukuchi Y and Takahashi K. Abrogation of the interaction between osteopontin and alphavbeta3 integrin reduces tumor growth of human lung cancer cells in mice. Lung cancer. 2007; 57:302-310.

7. Yin M, Soikkeli J, Jahkola T, Virolainen S, Saksela O and Holtta E. Osteopontin promotes the invasive growth of melanoma cells by activating integrin alphavbeta 3 and down-regulating tetraspanin CD9. The American journal of pathology. 2014; 184:842-858.

8. Sangaletti S, Tripodo C, Sandri S, Torselli I, Vitali C, Ratti C, Botti L, Burocchi A, Porcasi R, Tomirotti A, Colombo MP and Chiodoni C. Osteopontin shapes immunosuppression in the metastatic niche. Cancer research. 2014; 74:4706-4719.

9. Boyerinas B, Zafrir M, Yesilkanal AE, Price TT, Hyjek EM and Sipkins DA. Adhesion to osteopontin in the bone marrow niche regulates lymphoblastic leukemia cell dormancy. Blood. 2013; 121:4821-4831.

10. Kariya Y, Kanno M, Matsumoto-Morita K, Konno M, Yamaguchi $\mathrm{Y}$ and Hashimoto Y. Osteopontin O-glycosylation contributes to its phosphorylation and cell-adhesion properties. The Biochemical journal. 2014; 463:93-102.

11. Tuck AB, O’Malley FP, Singhal H, Tonkin KS, Harris JF, Bautista D and Chambers AF. Osteopontin and p53 expression are associated with tumor progression in a case of synchronous, bilateral, invasive mammary carcinomas. Archives of pathology \& laboratory medicine. 1997; 121:578-584.

12. Ue T, Yokozaki H, Kitadai Y, Yamamoto S, Yasui W, Ishikawa $\mathrm{T}$ and Tahara E. Co-expression of osteopontin and CD44v9 in gastric cancer. International journal of cancer. 1998; 79:127-132.
13. Wai PY and Kuo PC. Osteopontin: regulation in tumor metastasis. Cancer metastasis reviews. 2008; 27:103-118.

14. Shijubo N, Uede T, Kon S, Maeda M, Segawa T, Imada A, Hirasawa $\mathrm{M}$ and Abe $\mathrm{S}$. Vascular endothelial growth factor and osteopontin in stage I lung adenocarcinoma. American journal of respiratory and critical care medicine. 1999; 160:1269-1273.

15. Chambers AF, Wilson SM, Kerkvliet N, O’Malley FP, Harris JF and Casson AG. Osteopontin expression in lung cancer. Lung cancer (Amsterdam, Netherlands). 1996; 15:311-323.

16. Tuck AB, O'Malley FP, Singhal H, Harris JF, Tonkin KS, Kerkvliet N, Saad Z, Doig GS and Chambers AF. Osteopontin expression in a group of lymph node negative breast cancer patients. International journal of cancer. 1998; 79:502-508.

17. Agrawal D, Chen T, Irby R, Quackenbush J, Chambers AF, Szabo M, Cantor A, Coppola D and Yeatman TJ. Osteopontin identified as lead marker of colon cancer progression, using pooled sample expression profiling. Journal of the National Cancer Institute. 2002; 94:513-521.

18. Gotoh M, Sakamoto M, Kanetaka K, Chuuma M and Hirohashi S. Overexpression of osteopontin in hepatocellular carcinoma. Pathology international. 2002; 52:19-24.

19. Thalmann GN, Sikes RA, Devoll RE, Kiefer JA, Markwalder R, Klima I, Farach-Carson CM, Studer UE and Chung LW. Osteopontin: possible role in prostate cancer progression. Clin Cancer Res. 1999; 5:2271-2277.

20. Saitoh Y, Kuratsu J, Takeshima H, Yamamoto S and Ushio Y. Expression of osteopontin in human glioma. Its correlation with the malignancy. Laboratory investigation; a journal of technical methods and pathology. 1995; 72:55-63.

21. He B, Mirza M and Weber GF. An osteopontin splice variant induces anchorage independence in human breast cancer cells. Oncogene. 2006; 25:2192-2202.

22. Chae S, Jun HO, Lee EG, Yang SJ, Lee DC, Jung JK, Park KC, Yeom YI and Kim KW. Osteopontin splice variants differentially modulate the migratory activity of hepatocellular carcinoma cell lines. International journal of oncology. 2009; 35:1409-1416.

23. Tilli TM, Mello KD, Ferreira LB, Matos AR, Accioly MT, Faria PA, Bellahcene A, Castronovo V and Gimba ER. Both osteopontin-c and osteopontin-b splicing isoforms exert pro-tumorigenic roles in prostate cancer cells. The Prostate. 2012; 72:1688-1699.

24. Goparaju CM, Pass HI, Blasberg JD, Hirsch N and Donington JS. Functional heterogeneity of osteopontin isoforms in nonsmall cell lung cancer. J Thorac Oncol. 5:1516-1523.

25. Chuang CY, Chang H, Lin P, Sun SJ, Chen PH, Lin YY, Sheu GT, Ko JL, Hsu SL and Chang JT. Up-regulation of osteopontin expression by aryl hydrocarbon receptor via both ligand-dependent and ligand-independent pathways in lung cancer. Gene. 2012; 492:262-269. 
26. Bourguignon LY, Xia W and Wong G. Hyaluronanmediated CD44 interaction with p300 and SIRT1 regulates beta-catenin signaling and NFkappaB-specific transcription activity leading to MDR1 and $\mathrm{Bcl}-\mathrm{xL}$ gene expression and chemoresistance in breast tumor cells. The Journal of biological chemistry. 2009; 284:2657-2671.

27. Chen YJ, Wei YY, Chen HT, Fong YC, Hsu CJ, Tsai CH, Hsu HC, Liu SH and Tang CH. Osteopontin increases migration and MMP-9 up-regulation via alphavbeta3 integrin, FAK, ERK, and NF-kappaB-dependent pathway in human chondrosarcoma cells. Journal of cellular physiology. 2009; 221:98-108.

28. Fong YC, Liu SC, Huang CY, Li TM, Hsu SF, Kao ST, Tsai FJ, Chen WC, Chen CY and Tang CH. Osteopontin increases lung cancer cells migration via activation of the alphavbeta3 integrin/FAK/Akt and NF-kappaB-dependent pathway. Lung cancer (Amsterdam, Netherlands). 2009; 64:263-270.

29. Dai J, Peng L, Fan K, Wang H, Wei R, Ji G, Cai J, Lu B, Li B, Zhang D, Kang Y, Tan M, Qian W and Guo Y. Osteopontin induces angiogenesis through activation of PI3K/AKT and ERK1/2 in endothelial cells. Oncogene. 2009; 28:3412-3422.

30. Senger DR, Ledbetter SR, Claffey KP, PapadopoulosSergiou A, Peruzzi CA and Detmar M. Stimulation of endothelial cell migration by vascular permeability factor/ vascular endothelial growth factor through cooperative mechanisms involving the alphavbeta3 integrin, osteopontin, and thrombin. The American journal of pathology. 1996; 149:293-305.

31. Teramoto H, Castellone MD, Malek RL, Letwin N, Frank B, Gutkind JS and Lee NH. Autocrine activation of an osteopontin-CD44-Rac pathway enhances invasion and transformation by H-RasV12. Oncogene. 2005; 24:489-501.

32. Ailane $\mathrm{S}$, Long $\mathrm{P}$, Jenner $\mathrm{P}$ and Rose $\mathrm{S}$. Expression of integrin and CD44 receptors recognising osteopontin in the normal and LPS-lesioned rat substantia nigra. Eur J Neurosci. 2013; 38:2468-2476.

33. Dalal S, Zha Q, Daniels CR, Steagall RJ, Joyner WL, Gadeau AP, Singh M and Singh K. Osteopontin stimulates apoptosis in adult cardiac myocytes via the involvement of CD44 receptors, mitochondrial death pathway, and endoplasmic reticulum stress. Am J Physiol Heart Circ Physiol. 2014; 306:H1182-1191.

34. Wang KX and Denhardt DT. Osteopontin: role in immune regulation and stress responses. Cytokine \& growth factor reviews. 2008; 19:333-345.

35. Gao C, Guo H, Downey L, Marroquin C, Wei J and Kuo PC. Osteopontin-dependent CD44v6 expression and cell adhesion in HepG2 cells. Carcinogenesis. 2003; 24:1871-1878.

36. Lee JL, Wang MJ, Sudhir PR, Chen GD, Chi CW and Chen JY. Osteopontin promotes integrin activation through outside-in and inside-out mechanisms: OPN-CD44V interaction enhances survival in gastrointestinal cancer cells. Cancer research. 2007; 67:2089-2097.

37. Crawford HC, Matrisian LM and Liaw L. Distinct roles of osteopontin in host defense activity and tumor survival during squamous cell carcinoma progression in vivo. Cancer research. 1998; 58:5206-5215.

38. Wai PY, Guo L, Gao C, Mi Z, Guo H and Kuo PC. Osteopontin inhibits macrophage nitric oxide synthesis to enhance tumor proliferation. Surgery. 2006; 140:132-140. 